\title{
Individual Differences in Situation-Behavior Profiles: A Triple Typology Model
}

\author{
Kristof Vansteelandt and Iven Van Mechelen \\ Katholieke Universiteit Leuven
}

\begin{abstract}
A model is proposed to represent individual differences in situation-behavior profiles. The model consists of 3 components: (a) Typologies of person, situation, and behavior classes; (b) hierarchical relations between the classes of each typology; and (c) a characterization of the person types in terms of different sets of if (situation class) then (behavior class) rules by which the 3 typologies are linked to one another. A data analysis technique (INDCLAS) is available to induce a triple typology model from empirical data. To reveal the psychological mechanisms behind such a model, the classes of the model can be related to situation, behavior, and person features. As a result, person types can be interpreted in terms of systems of cognitive-affective variables that mediate between active situation features and behavioral manifestations. This is illustrated with a study on selfreported hostile behavior in frustrating situations.
\end{abstract}

According to Bem (1983), the fundamental scientific task for personality research is

\begin{abstract}
to convert observations of particular persons behaving in particular ways in particular situations into assertions that certain kinds of persons will behave in certain kinds of ways in certain kinds of situations, that is, to construct triple typologies or equivalence classes - of persons, of behaviors, and of situations - and to fashion theories of personality that relate these equivalence classes to one another. (p. 566)
\end{abstract}

Several authors other than Bem have underscored the importance of studying personality in terms of meaningful patterns of stability and change in well-defined groups of behaviors in relation to well-defined groups of situations (Allport, 1937; Claeys, Timmers, \& Phalet, 1993; Golding, 1975; Mischel \& Shoda, 1995; Olweus, 1976; Pervin, 1976; Shoda, Mischel, \& Wright, 1993, 1994; Wright \& Mischel, 1987). In particular, Wright and Mischel, building on earlier work of Alston (1975), proposed a conditional approach to the study of personality, in which the fundamental unit of observation is not the unconditional probability of behavior but rather the conditional probability of a certain type of behavior given types of situations or psychological conditions. Within this context, differences between (classes of) persons may be conceived as differences in if ( situation class) then (behavior class) rules. Wright and Mischel further assumed that the situation category as well as the behavior

Kristof Vansteelandt and Iven Van Mechelen, Department of Psychology, Katholieke Universiteit Leuven, Leuven, Belgium.

The research reported in this article was supported by North Atlantic Treaty Organization Grant CRG921321. We thank Seymour Rosenberg for his helpful comments on an earlier version of this article.

Correspondence concerning this article should be addressed to Kristof Vansteelandt, Department of Psychology, Katholieke Universiteit Leuven, Tiensestraat 102, B-3000 Leuven, Belgium. Electronic mail may be sent to kristof.vansteelandt@psy.kuleuven.ac.be. category are prototype-based categories with vague boundaries and elements that vary from highly central to more peripheral category members; the linking rules between those categories are further assumed to be probabilistic.

In this article, a set-theoretical, comprehensive model is proposed that formalizes the above-mentioned ideas. This model consists of typologies of persons, situations, and behaviors, each of which is hierarchically organized. The three typologies are linked to one another in that each person class is characterized in terms of a set of if (situation class) then (behavior class) rules.

The article consists of two parts. In the first part, the formal model is discussed, together with the associated method of data gathering and data analysis; next, the model is illustrated in a study on self-reported hostile behavior. The second part of the article outlines the principles of revealing psychological mechanisms underlying a triple typology model; these are illustrated with the model for self-reported hostile behavior.

\section{Model}

In explaining the triple typology model, we assume that data are available that indicate which persons display which behaviors in which situations for all possible combinations of persons, situations, and behaviors. Technically speaking, this is called a three-way, three-mode data set (Carroll \& Arabie, 1983). The triple typology model is a formal, comprehensive model for this type of data. As to the latter, it is similar to other three-way models, including the model of three-way factor analysis (Levin, 1965). Unique features of the triple typology are its three components: (a) classes, (b) hierarchical relations, and (c) a linkage structure. These three components are discussed in the following sections. For reasons of argument, the model is first described in a deterministic way; it is later shown that the application of the model to empirical data may result in a probabilistic, prototype-based interpretation. 


\section{Person Classes, Situation Classes, and Behavior Classes}

Two persons belong to the same person class if, in each possible situation, they display the same set of behaviors (that may differ across situations). Each person class can be conceived as a person type with the presence-absence of each behavior in each situation as features. Hence, the model fits more of a type theory of personality than a trait theory (Bem, 1983).

Similarly, two situations belong to the same situation class if for each person it holds that both situations elicit the same set of behaviors from that person. This set of behaviors may, however, be different depending on the person taken into consideration. For example, Situation $\mathrm{A}$, in which a person learns that his or her important book has been lost by someone else, and Situation $\mathrm{B}$, in which a person learns that someone else has opened his or her personal mail, may belong to the same situation class; from Person $\mathrm{X}$ both situations may elicit sarcastic remarks, whereas from Person Y, both situations may elicit feelings of tension but no verbal aggressive behavior. Hence, situations that belong to the same situation class may be considered functionally equivalent (Shoda et al., 1994), and this functional equivalence holds for all persons. On top of that, it is possible that for certain (but not all) persons, situations that belong to different situation classes are also functionally equivalent.

Finally, two behaviors belong to the same behavior class when for each person and for each situation it holds that the person displays either both behaviors or neither of the two behaviors in that situation. This implies that the classification of behaviors is based on co-occurence across all persons and across all situations. One may note that, in addition, it is possible that for certain (but not all) persons, behaviors that belong to different behavior classes also co-occur across all situations.

\section{Relations Between the Classes of One Entity}

Hierarchical organizations have been recognized as central structuring principles in personality theory (Hampson, John, \& Goldberg, 1986; John, Hampson, \& Goldberg, 1991; Murtha, Kanfer, \& Ackerman, 1996; Price \& Bouffard, 1974). Hampson et al. pointed out that for constructs to be organizable in a hierarchical structure, there have to be differences in breadth in the construct domain, hierarchically higher classes generally being broader than hierarchically lower classes.

In the triple typology model, the person, situation, and behavior classes are hierarchically organized. The three hierarchies can be graphically represented. A class is hierarchically below another class whenever in the graphical representation it is below that class and connected to it by a line. As an example, a hierarchy of three hypothetical person types (classes) is given in Figure 1. In each class, it is indicated whether the persons of that class tum away, hit someone, or feel tense in a low and a high frustrating situation.

With regard to the person classes in our model, the breadth of a class may be defined in terms of the number of situationbehavior combinations associated with that class. Person classes characterized by more situation-behavior combinations are broader than person classes characterized by fewer situation- behavior combinations. For example, in Figure 1, Person Type 3 , which is hierarchically higher than Person Types 1 and 2, is characterized by more situation-behavior combinations. Analogously, breadth of situation classes and behavior classes may be defined in terms of person-behavior combinations and personsituation combinations, respectively.

A second and more stringent requirement that, according to Hampson et al. (1986), has to be fulfilled for concepts to be organizable in a hierarchy is the condition of asymmetric class inclusion, which requires that all properties of a concept at a lower level in the hierarchy also apply to the hierarchically higher concept, the reverse not necessarily being true. This implies that a hierarchically lower concept is included in the hierarchically higher concept in terms of properties.

With regard to the person types in our model, an asymmetric inclusion relation may be defined in terms of the associated situation-behavior combinations. In particular, a person class is hierarchically below another person class if whenever the persons of the hierarchically lower person class display a certain behavior in a certain situation, then the persons of the hierarchically higher person class also display that behavior in that situation, the reverse not necessarily being true. In Figure 1, for example, the persons of Person Type 2 turn away and feel tense in high frustration situations, and this is also the case for persons of Person Type 3. On the other hand, the persons of Person Type 3 also display the same behaviors in a low frustration situation, whereas this is not the case for the persons of Person Type 2.

For the situation classes, asymmetric inclusion relations are defined in terms of associated person-behavior combinations. A similar hierarchical arrangement of situations was discussed by Cantor, Mischel, and Schwartz (1982) and Murtha et al. (1996). Asymmetric inclusion relations for the behavior classes are defined in terms of person-situation combinations.

\section{Linking Structure of the Triple Typology}

The third component of the triple typology model is the linkage of the three typologies into a single integrated structure. The linkage of the three typologies may be looked at as a characterization of each person class in terms of a set of if ( situation class) then (behavior class) rules (Wright \& Mischel, 1987). An if (situation class) then (behavior class) rule indicates that whenever a person of the person class in question faces a situation of the situation class, this person will display all behaviors from the behavior class. In this way, the different person classes are characterized in terms of different situation-behavior profiles.

\section{Fuzzy Classes and Probabilistic Linking Rules}

The triple typology model as presented above is a categorical and deterministic model, the different classes of which are monothetic categories. For example, persons who belong to the same person class are assumed to display exactly the same set of behaviors in each situation. A similar statement holds for the situation classes and the behavior classes, and also the if (situation class) then (behavior class) rules as presented above are deterministic in nature. 


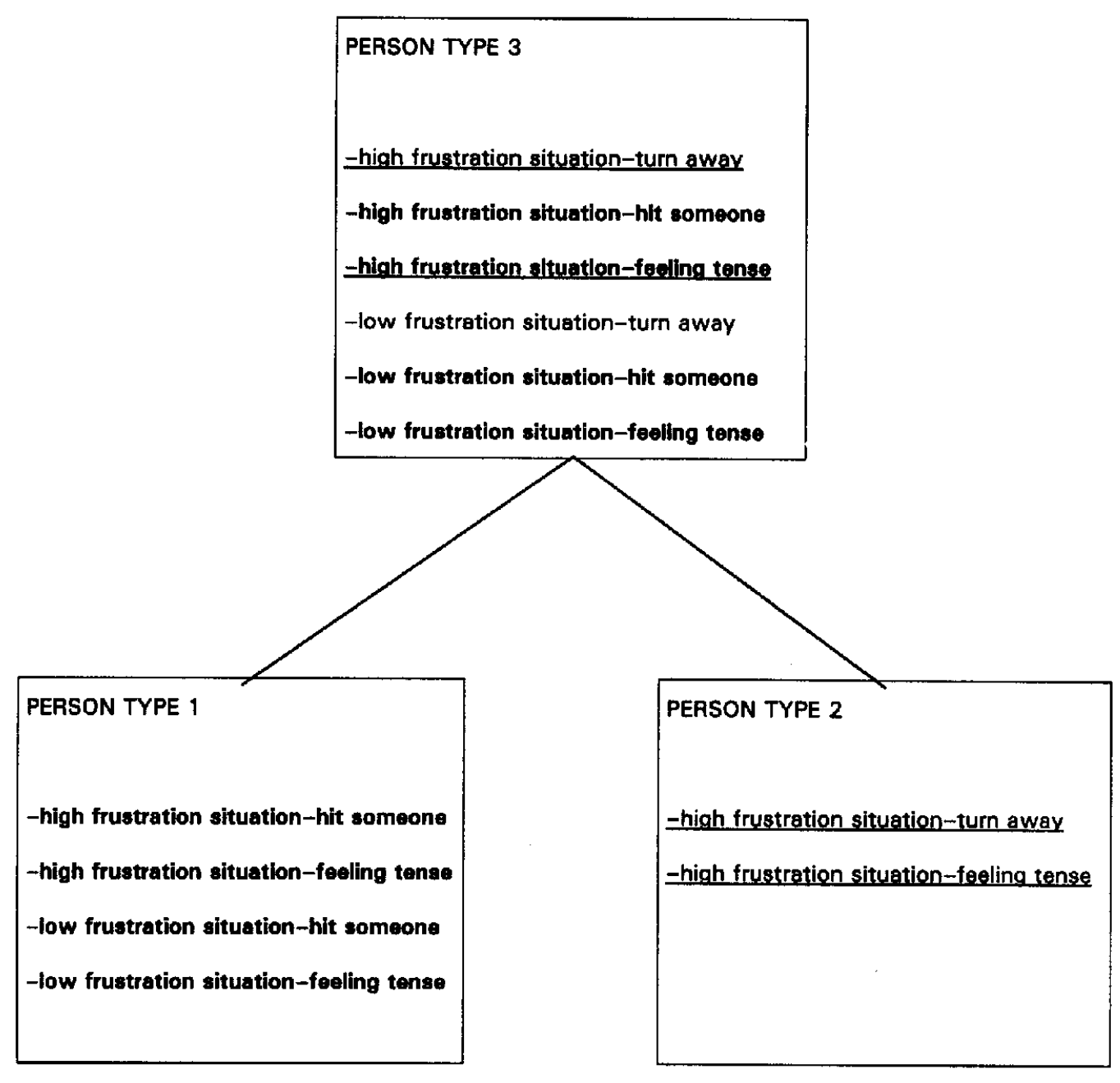

Figure 1. Hypothetical example of the hierarchical organization of three person types. Situation-behavior combinations of Person Type 3 that appear in boldface are shared with Person Type 1; those that are underlined are shared with Person Type 2; and the one that is both boldface and underlined is shared with both Person Types 1 and 2.

In the analysis of real data, however, parsimonious models with a less than perfect fit to the data are preferred over complex models with a perfect fit. An algorithm (individual differences hierarchical classes analysis, or INDCLAS) is available that, given a complexity bound, induces a triple typology model with an optimal-but usually less than perfect-fit from a given dataset (Leenen, Van Mechelen, De Boeck, \& Rosenberg, in press). For the triple typology model, a less than perfect fit implies that each class corresponds to a fuzzy category with members that vary in centrality as in many natural categories (Rosch, Mervis, Gray, Johnson, \& Boyes-Braem, 1976). For example, the degree of centrality of a person to a person class depends on the match between the features of that individual person and the features of the class prototype specified in the model; these features are defined as the presence or absence of behaviors in each situation. Similar implications hold for the situations and the behaviors. The conception of situation classes and behavior classes as fuzzy categories is consistent with Wright and Mischel's (1987) theory.

The use of less than perfect models finally also results in probabilistic rather than deterministic if - then rules. For each if (situation class) then (behavior class) rule, one may calculate the conditional probability that a person of the person type under consideration displays a behavior of the behavior class in a situation of the situation class. It is also possible to calculate the conditional probabilities for combinations of a subgroup of persons, situations, or behaviors. In general, these conditional probabilities will be affected by class centrality with higher probabilities occurring for more central persons, situations, and behaviors ( see also Wright \& Mischel, 1987). More information on the INDCLAS algorithm (Leenen et al., in press) is provided in the Method section. 


\section{Study 1}

In this study, the triple typology model is illustrated through an investigation of self-reported hostile behavior. Hostility was chosen, consistent with earlier contextualized studies of this domain (Endler \& Hunt, 1968; Mischel, 1993; Rosenzweig, 1976; Shoda et al., 1994; Wright \& Mischel, 1987). The present study is mainly exploratory in nature, and its aim is to test the utility of the triple typology model and the associated data analysis.

\section{Method}

Participants. The participants in this study were 54 first-year psychology students. Their participation was in partial fulfillment of a requirement to participate in research. The group consisted of 14 men and 40 women (which reflects the sex proportions of 1st-year psychology students in Belgium). The average age of the participants was 19 (SD $=1.3$ ).

Materials. The materials were based on two Situation-Response Inventories of Hostility developed by Endler and Hunt (1968). These inventories were chosen because, in previous research, they appeared to be suitable to retrieve individual profile differences in hostile behavior (e.g., Endler \& Hunt, 1968; Zuroff, 1982); moreover, the inventories were constructed for a student population, a sample that is also used in the present study. Endler and Hunt selected situations with which students may be familiar through direct or vicarious experience. Several of their situations were taken from samples used by Hunt, Cole, and Reis (1958) to evoke anger, and some of them represent what Rosenzweig (1944) considered to be personal frustrating circumstances or impersonal frustrating agents. The samples of behaviors include (a) certain physiological reactions typically found in anger and (b) extrapunitive reactions to frustration (Rosenzweig, 1944).

All combinations of situations and behaviors from the two inventories were retained, which resulted in an inventory of 23 situations and 15 behaviors. An example of a situation is "Your instructor unfairly accuses you of cheating on an examination", examples of behaviors are to curse, become tense, and feel irritated. The full set of situations and behaviors is presented in Figures 2 and 3, respectively.

Procedure. For each situation-behavior combination, the participant had to indicate on a 3-point scale the extent to which he or she displayed the behavior in the situation $(0=$ you do not display this behavior in this situation, 1 = you display this behavior in this situation to a limited extent, 2 = you display this behavior in this situation to a strong extent). First, the participant had to judge the first situation with respect to all behaviors, next he or she had to judge the second situation, and so forth. The situations were presented in random order, and within each situation, the behaviors were also presented in random order.

Analysis. The Person $\times$ Situation $\times$ Behavior data were analyzed by means of the INDCLAS algorithm (Leenen et al., in press). This algorithm is a three-way extension of the hierarchical classes analysis (HICLAS) algorithm, developed by De Boeck and Rosenberg (1988) to fit the HICLAS model to two-way, two-mode (e.g., person by situation) binary data. The HICLAS model and algorithm have appeared to be very useful in a variety of substantive applications (see, e.g., De Boeck \& Van Mechelen, 1990; Ogilvie \& Ashmore, 1991; Reid \& Deaux, 1996; Rosenberg, 1989); for overviews of the hierarchical classes approach, see De Boeck, Rosenberg, and Van Mechelen (1993) and Rosenberg, Van Mechelen, and De Boeck (1996).

The INDCLAS algorithm operates on a three-way, three-mode dichotomized data matrix in order to find the best fitting INDCLAS model (or triple typology model). It is an alternating least squares type of algorithm, which alternates between the three modes of the data array until an iteration does not improve the goodness of fit of the solution to the data anymore. The algorithm further generates a series of INDCLAS models of increasing complexity in order to determine the optimal rank for the data. The rank of the model is reflected by the maximum number of classes allowed at the base of the hierarchies of the three modes. The user can determine the optimal rank for the final solution (comparable to the number of factors extracted in factor analysis) on the basis of a goodness of fit by rank plot.

HICLAS and INDCLAS are similar to existing standard clustering procedures that yield series of partitions of sets of objects. The following distinctive features of HICLAS and INDCLAS can, however, be pointed out: (a) Both algorithms operate on the raw dichotomized two- or threeway, two- or three-mode data rather than on derived proximity data, (b) both algorithms generate a simultaneous clustering of the elements of the two or three modes involved in the data, and (c) each clustering is organized on the basis of subset-superset relations.

In this study, the Person $\times$ Situation $\times$ Behavior data were first dichotomized (zero vs. one or two) and analyzed with INDCLAS in Ranks 1 to 7 . The global goodness of fit of each resulting model and the goodness of fit of each single person, situation, and behavior were evaluated in terms of the proportion of concordances between that model and the data. The choice of the final model was based on a scree test on the global goodness of fit by rank plot. The stability of the final solution was checked by an odd-even split of the sample of persons. Reliability then was examined by comparing for each subsample the goodness of fit of an exploratory and a confirmatory INDCLAS analysis (in which the situation and behavior structure of the final model was imposed).

\section{Results}

A triple typology model of Rank 3 was selected based on a scree test; the global goodness of fit for this model was .73 . This solution appeared to be reliable, the goodness-of-fit values for the exploratory and confirmatory analysis being .75 and .73 for the odd subsample, respectively, and .74 and .73 for the even subsample, respectively. The final model comprised seven person classes, three situation classes, and six behavior classes. ${ }^{1}$

The different situation classes and the goodness-of-fit values for each single situation are shown in Figure 2. Figure 2 also represents the hierarchical relations between the different situation classes. For example, if a certain person displays a certain behavior in a situation of Situation Class S1 (e.g., waiting in a restaurant to be served), he or she will also display the same behavior in a situation of Situation Class S2 (e.g., when the bus fails to stop). It is clear from Figure 2 that the three situation classes make up a linear hierarchy that may be conceived as a quantitative dimension (Gati \& Tversky, 1982). This dimension could be tentatively interpreted as a frustration dimension with Situation Class $\mathrm{S} 1$ containing the least frustrating, Situation Class S2 containing the moderately frustrating, and Situation Class S3 containing the most frustrating situations. The asymmetric inclusion relation then simply means that if a certain person displays a certain behavior in a less frustrating situation, then he or she will also display that behavior in more frustrating situations.

\footnotetext{
${ }^{1}$ In addition, there was a zero class containing one person and a zero class containing two situations. Those zero classes have empty sets of associated situation-behavior combinations and person-behavior combinations, respectively.
} 

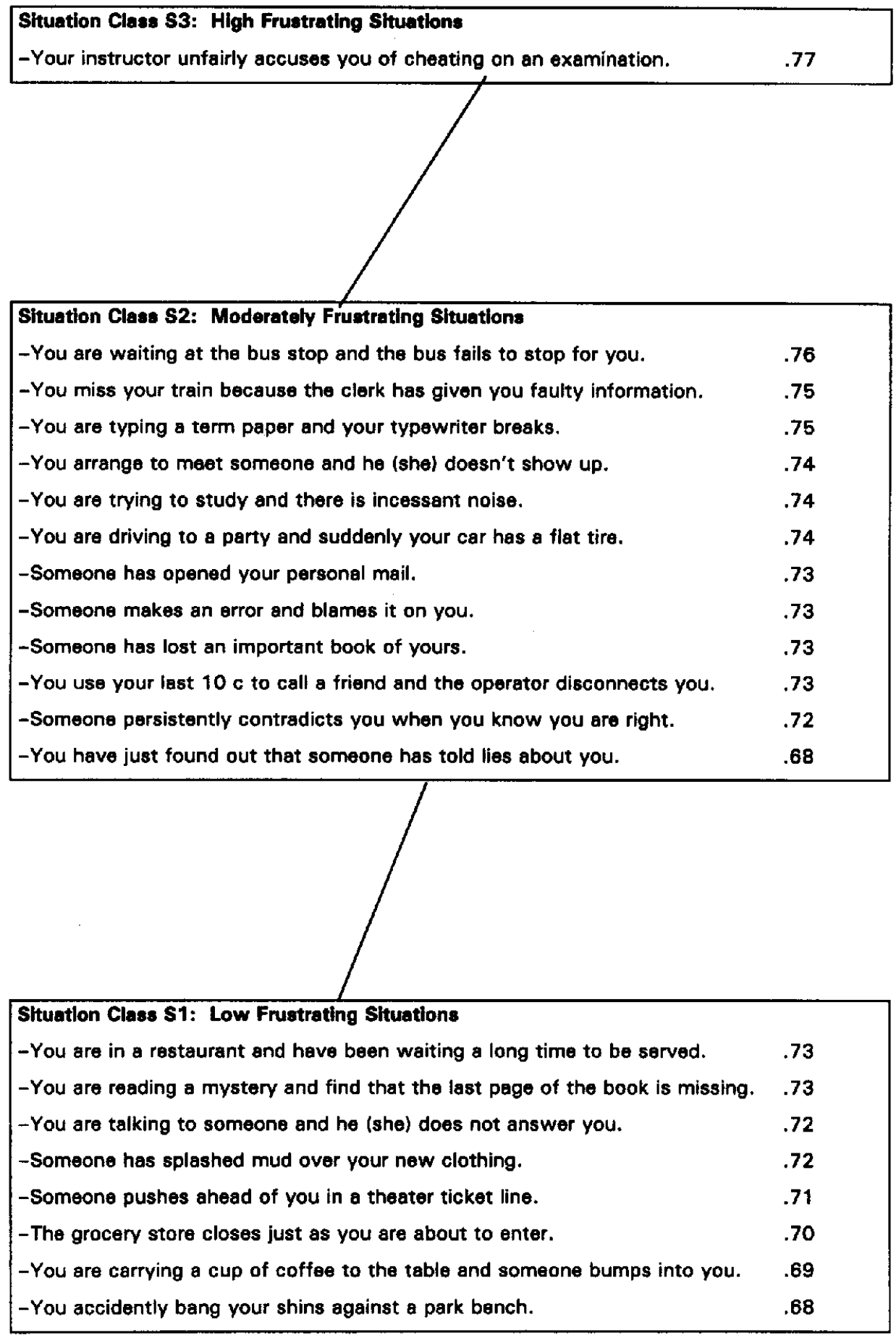

Figure 2. Hierarchical organization of three situation classes and goodness-of-fit values for all situations. From " $S-R$ Inventories of Hostility and Comparisons of the Proportions of Variance from Persons, Behaviors, and Situations for Hostility and Anxiousness," by N. S. Endler and J. M. Hunt, 1968, Journal of Personality and Social Psychology, 9, pp. 310-311. Copyright 1968 by the American Psychological Association. Adapted by permission of the author. 


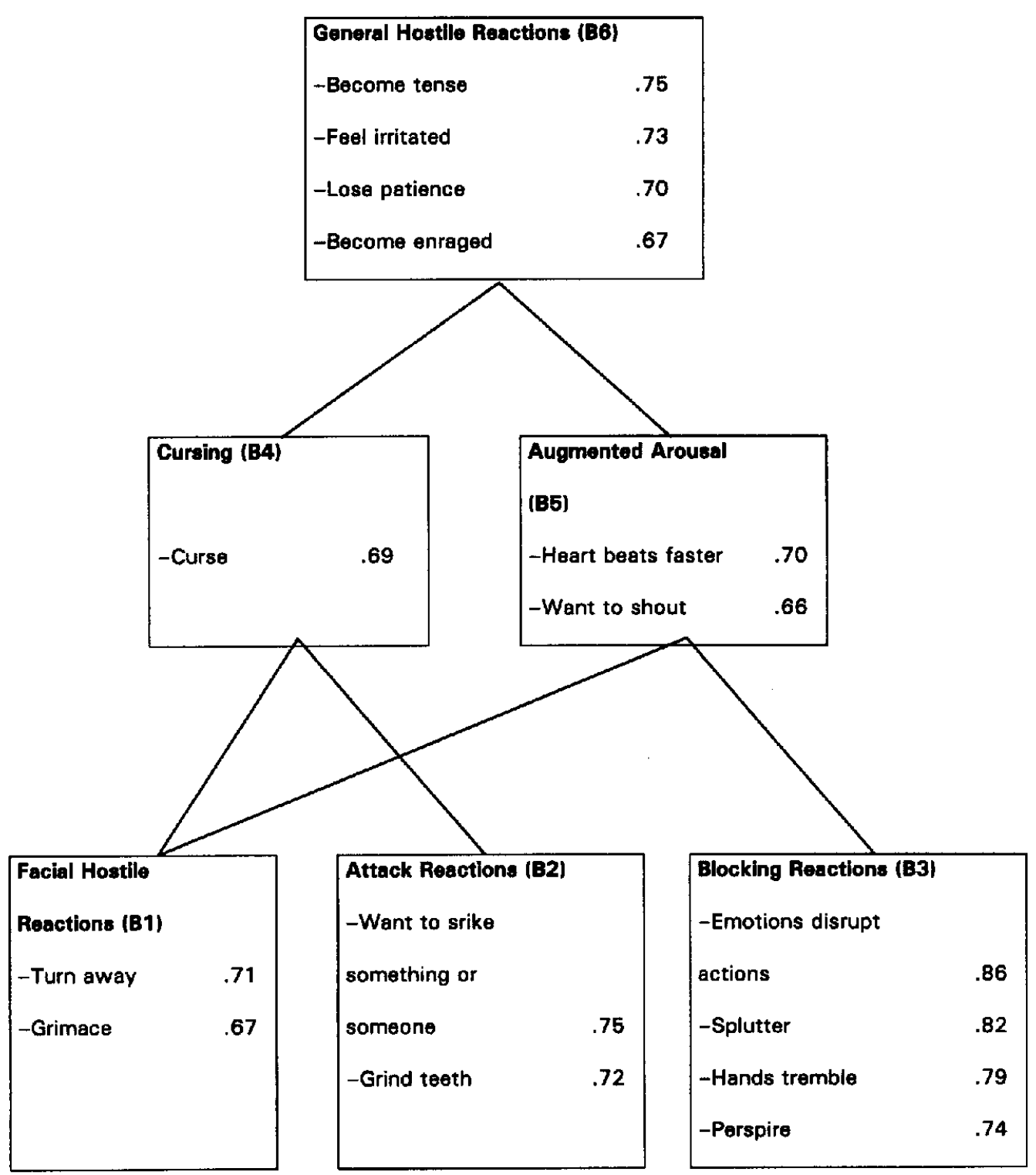

Figure 3. Hierarchical organization of six behavior classes and goodness-of-fit values for all behaviors. From "S-R Inventories of Hostility and Comparisons of the Proportions of Variance from Persons, Behaviors, and Situations for Hostility and Anxiousness," by N. S. Endler and J. M. Hunt, 1968, Journal of Personality and Social Psychology, 9, p. 311. Copyright 1968 by the American Psychological Association. Adapted by permission of the author.

The hierarchy of the behaviors and the associated goodnessof-fit values are shown in Figure 3. The behaviors of Behavior Class B6, which is at the top of the hierarchy, are displayed across a wide range of situations by each person, and these behaviors can be interpreted as broad, general hostile reactions (B6). Behavior classes that are lower in the hierarchy include more specific reactions. We tentatively label them as facial hostile reactions ( $\mathrm{B} 1)$, attack reactions ( $\mathrm{B} 2)$, blocking reactions (B3), cursing (B4), and augmented arousal (B5). One may note that the behaviors at the right side of the hierarchy (i.e., the behaviors of B3, B5, and B6) refer to more physiologic and automatic reactions.

The full triple typology model is given in Table 1 . This table presents for each person class the number of persons belonging to that class, their range of goodness-of-fit values (reflecting their differences in prototypicality), and the corresponding set of if-then rules. For example, for the persons of Person Type 5 (which includes 13 persons, with goodness-of-fit values varying from .66 to .82 ), it holds that if a person from this person class is, for example, in a restaurant and has been waiting a long time 
Table 1

A Taxonomy of Person Types Characterized by If (Situation Class) Then (Behavior Class) Rules

\begin{tabular}{|c|c|c|c|c|c|c|c|c|c|}
\hline \multirow{2}{*}{$\begin{array}{l}\text { Person type and } \\
\text { situation class }\end{array}$} & \multirow[b]{2}{*}{$n$} & \multirow{2}{*}{$\begin{array}{l}\text { Goodness-of- } \\
\text { fit range }\end{array}$} & \multicolumn{7}{|c|}{ Behavior class } \\
\hline & & & B1: Facial & B2: Attack & B3: Blocking & B4: Cursing & B5: Augmented arousal & B6: General & $\Sigma \mathbf{B}$ \\
\hline Pl: Person Type 1 & 6 & $.69-.77$ & & & & & & & \\
\hline S1: Low & & & $1(.67)$ & $0(.08)$ & $0(.14)$ & $1(.65)$ & $1(.39)$ & $1(.56)$ & 1 \\
\hline S2: Moderate & & & $1(.69)$ & $0(.19)$ & $0(.24)$ & $1(.86)$ & $1(.69)$ & $1(86)$ & 1 \\
\hline S3: High & & & $1(.58)$ & $0(.33)$ & $0(.46)$ & $1(.33)$ & $1(.92)$ & $1(.83)$ & 1 \\
\hline P2: Person Type 2 & 3 & $.65-.76$ & & & & & & & \\
\hline S1: Low & & & $0(.35)$ & $0(.13)$ & $0(.04)$ & $0(.71)$ & $0(.25)$ & $0(.33)$ & 0 \\
\hline S2: Moderate & & & $0(.24)$ & $1(.25)$ & $0(.10)$ & $1(.72)$ & $0(.24)$ & $1(.58)$ & 1 \\
\hline S3: High & & & $0(.00)$ & $1(.50)$ & $0(.25)$ & $1(.67)$ & $0(.67)$ & $1(.83)$ & 1 \\
\hline P3: Person Type 3 & 7 & $.68-.80$ & & & & & & & \\
\hline S1: Low & & & $0(.42)$ & $0(.04)$ & $0(.05)$ & $0(.29)$ & $0(.18)$ & $0(.29)$ & 0 \\
\hline S2: Moderate & & & $0(.43)$ & $0(.11)$ & $0(.10)$ & $0(.52)$ & $0(.39)$ & $0(.49)$ & 0 \\
\hline S3: High & & & $0(.50)$ & $0(.14)$ & $1(.75)$ & $0(.29)$ & $1(.79)$ & $1(.79)$ & 1 \\
\hline P4: Person Type 4 & 3 & $.60-.79$ & & & & & & & \\
\hline S1: Low & & & $1(.73)$ & $0(.56)$ & $0(.21)$ & $1(.79)$ & $1(.40)$ & $1(.59)$ & 1 \\
\hline S2: Moderate & & & $1(.57)$ & $1(.68)$ & $0(.24)$ & $1(.97)$ & $1(.71)$ & $1(.82)$ & 1 \\
\hline S3: High & & & $1(.50)$ & $1(.67)$ & $0(.25)$ & $1(.33)$ & $1(.67)$ & $1(.92)$ & 1 \\
\hline P5: Person Type 5 & 13 & $.66-.82$ & & & & & & & \\
\hline S1: Low & & & $1(.75)$ & $0(.06)$ & $0(.16)$ & $1(.50)$ & $1(.41)$ & $1(.57)$ & 1 \\
\hline S2: Moderate & & & $1(.78)$ & $0(.23)$ & $0(.33)$ & $1(.74)$ & $1(.74)$ & $1(.84)$ & 1 \\
\hline S3: High & & & $1(.81)$ & $0(.19)$ & $1(.92)$ & $1(.54)$ & $1(.92)$ & $1(.81)$ & 1 \\
\hline P6: Person Type 6 & 9 & $.66-.79$ & & & & & & & \\
\hline S1: Low & & & $0(.48)$ & $0(.20)$ & $0(.05)$ & $0(.51)$ & $0(.16)$ & $0(.35)$ & 0 \\
\hline S2: Moderate & & & $0(.33)$ & $1(.46)$ & $0(.12)$ & $1(.76)$ & $0(.41)$ & $1(.71)$ & 1 \\
\hline S3: High & & & $0(.17)$ & $1(.39)$ & $1(.89)$ & $1(.44)$ & $1(.78)$ & $1(.72)$ & 1 \\
\hline P7: Person Type 7 & 12 & $.59-.79$ & & & & & & & \\
\hline S1: Low & & & $1(.71)$ & $0(.58)$ & $0(.27)$ & $1(.73)$ & $1(.57)$ & $1(.65)$ & 1 \\
\hline S2: Moderate & & & $1(.74)$ & $1(.71)$ & $0(.44)$ & $1(.85)$ & $1(.77)$ & $1(.86)$ & 1 \\
\hline S3: High & & & $1(.79)$ & $1(.67)$ & $1(.98)$ & $1(.67)$ & $1(.92)$ & $1(.83)$ & 1 \\
\hline
\end{tabular}

Note. A 0 indicates that a behavior is not displayed; a 1 indicates that a behavior is displayed. In each cell entry, the probability of the if (situation class) then (behavior class) rule of a person type is given between parentheses. The abbreviations $\mathbf{S} 1, \mathbf{S} 2$, and $\mathbf{S} 3$ refer to Situation Classes 1,2 , and 3; tentative labels for these classes are low frustrating situations, moderately frustrating situations, and high frustrating situations, respectively; B1 through B6 refer to Behavior Classes 1 through 6, respectively; tentative labels for these behavior classes are facial hostile reactions, attack reactions, blocking reactions, cursing, augmented arousal, and general hostile reactions. $\Sigma$ B refers to the aggregated behaviors: A 0 indicates that no hostile behavior is displayed, and a 1 indicates that at least one class of hostile behaviors is displayed in the situations of the situation class involved. Boldface is used to illustrate the hierarchical organization of person types, situation classes, and behavior classes. Specifically, in this illustration, it can be derived from the table that Person Type 3 is hierarchically below Person Type 7.

to be served ( $\mathrm{S} 1$ : low frustrating situation) or is waiting at the bus stop and the bus fails to stop ( $S 2$ : moderately frustrating situation), then he or she will turn away or grimace (B1: facial hostile reactions), curse (B4: cursing), have a faster heart rate, want to shout (B5: augmented arousal), and feel irritated (B6: general hostile reactions). If that same person is unfairly accused by his or her instructor of cheating on an examination (S3: high frustrating situation), then, besides the above-mentioned behaviors, he or she will also respond by emotions that disrupt actions (B3: blocking reactions). It is important to note that the model also predicts that behaviors from certain behavior classes will not be displayed under some conditions. For example, for a person of Person Type 5, it holds that when that person is unfairly accused of cheating on an examination (S3: high frustrating situation), then he or she will not respond by grinding his or her teeth or by wanting to hit something or someone (B2: attack reactions ).

For each if-then rule, one may further calculate the conditional probability that the rule holds in the data. For example, the probability that a person of Person Type 5 will display a general hostile reaction (B6) in a moderately frustrating situation (S2) is .84. Similarly, conditional probabilities may be calculated for negative predictions.

In general, conditional probabilities will be higher if only central persons, situations, or behaviors are considered. As an example, one may subdivide Person Type 5 into a peripheral and a central group based on a median split of their goodnessof-fit values; the conditional probability that a person of the peripheral -central group will display a general hostile reaction (B6) in a moderately frustrating situation (S2) is .76 and .91, respectively. Similarly, one could subdivide $\mathrm{S} 2$ and B6. The conditional probability that a central person of Person Type 5 will display a central behavior from the general hostile reactions class (B6) in a central situation of the moderately frustrating situation class (S2) is .99 .

It may be noted that the hierarchical organization of the person types can be derived from Table 1. For example, one can see from Table 1 that Person Type 3 is hierarchically below Person Type 7 in that (a) the area of the positive predictions for Person Type 3 (the area in which boldface is used) is smaller 
than the corresponding (boldface) area for Person Type 7, which reflects the fact that Person Type 7 is broader than Person Type 3 , and (b) the area of Person Type 3 is included in the area of Person Type 7, which reflects the asymmetric inclusion relation between Person Type 3 and Person Type 7. In the same way, the hierarchical organization of the situation classes and the behavior classes can be derived from Table 1 .

\section{Discussion}

The formal, comprehensive model as illustrated above represents the complex interplay of persons, situations, and behaviors in terms of three hierarchically organized typologies that are linked to each other by a set of implicational linking rules. An important feature of the model is its association with a dataanalytic technique by which instances of the model can be derived in an inductive way from person by situation by behavior data. As a model for the latter type of data, the triple typology model is similar to other three-way models, including the model of three-way factor analysis (Levin, 1965).

Beyond the latter models, the triple typology model is consistent with a number of major theoretical ideas. As such, the model meets Bem's (1983) call to convert observations of particular persons behaving in particular ways in particular situations into assertions that certain kinds of persons behave in certain kinds of ways in certain kinds of situations. The fuzzy class membership for the three types of classes of the model that arises in the application of the model to empirical data is in line with prototype-based accounts of classification in the personality domain advocated by several authors (Cantor \& Mischel, 1979; Cantor et al., 1982; Schutte, Kenrick, \& Sadalla, 1985; Wright \& Mischel, 1987). The hierarchical organization of the classes is based on what is considered a central structuring principle in personality theory (Hampson et al., 1986; Murtha et al., 1996). The linkage of the three typologies in terms of if (situation class) then (behavior class) rules formalizes Wright and Mischel's conditional view on individual differences.

With respect to individual differences, it is interesting to note that the triple typology model captures differences between person types at several levels. At a global level, the model represents differences in terms of associated sets of situation-behavior combinations. Within this context, person types that are in a subset-superset relation to one another may be considered quantitatively different, whereas person types that are not in such a relation are qualitatively different. In the model, these two kinds of differences are directly represented by the hierarchical organization in that quantitatively different person types are, unlike qualitatively different person types, hierarchically related. At a more specific level, one may also derive from the model differences between person types in terms of behavior classes displayed in a single situation class (e.g., S3). Furthermore, it is also possible to examine differences between person types at an aggregated level. In the hostility study, for example, after aggregation across behavior classes, it appears that there are person types that display hostile behavior in Situation Classes S1, S2, and S3 (Person Types 1, 4, 5, and 7); person types that display hostile behavior in Situation Classes S2, and S3 (Person Types 2 and 6); and person types that only display hostile behavior in Situation Class S3 (Person Type 3). At the specific and at the aggregated level, one may also draw a distinction between quantitative and qualitative differences, quantitative differences again being reflected in subset-superset relations. Otherwise, it is interesting to note that, in the hostility example, at the aggregated level there are only quantitative differences between person types. This necessarily follows from the fact that the hierarchy of situation classes in the model constitutes a Guttman scale.

\section{Study 2}

Once a triple typology model has been constructed, the question arises as to what the psychological mechanisms behind it are. Why do different persons (situations, behaviors) belong to the same person (situation, behavior) class (Bem, 1983; Funder \& Colvin, 1991; Golding, 1975; Mischel \& Peake, 1982; Olweus, 1976; Shoda et al., 1994)? What is the substantive basis of the hierarchical relations and of the if-then rules of the model?

Mischel and Shoda (1995) argued that individual differences in if ( situation) then (behavior) profiles constitute a kind of behavioral signature that reflects the cognitive affective person system (CAPS) - a system of cognitive-affective units that mediate between the context or situation and the person's behavioral manifestations. These three aspects - situation, behavior, and cognitive-affective units - are now discussed in relation to the triple typology model.

To conceptualize the context or situation, Shoda et al. (1994) made a distinction between nominal situations and situations characterized in terms of active psychological features. Nominal situations are defined by the setting in which they occur. For example, a university restaurant is a nominal situation within a university setting. Active psychological features are situational characteristics that have an impact on behavior or that determine the meaning of the situation. Active psychological features could, for example, be whether one is alone, with another person, or with a group of persons in the situation, and whether one is familiar with the other person( $s$ ) in the situation or not, and so forth. Shoda et al. argued that it is psychologically more useful to investigate situations in terms of their active psychological features rather than in nominal terms. With regard to the triple typology model, it is straightforward to hypothesize that the functional equivalence of situations that belong to the same situation class (or cluster of situation classes) is based on the fact that the situations in question share the same active psychological features. Hence, the question as to what the psychological mechanisms are behind the grouping of situations implies a search of features that are common to the situations of the situation class (es) under consideration (and that are distinctive with respect to the situations of all other situation classes).

Behavioral manifestations, from a CAPS viewpoint, occur if they are linked to activated cognitive-affective units. One could further hypothesize that the latter units, more particularly, are linked to broader behavioral channels that include several specific responses. As an example, one may consider the cardiovascular channel including responses such as high heart rate or increased blood pressure. Responses that are part of the same 
response channel may be expected to co-occur. Individual differences in response specificity (Asendorpf, 1988) can further be attributed to differences in preferences for distinct response channels. For example, some persons may show a preference for the channel of overt anger behaviors, whereas others may suppress such behaviors. With regard to the triple typology model, (clusters of) behavior classes may be hypothesized to correspond to well-defined behavior channels, characterized by distinct behavior features. The latter are to be retrieved by the researcher.

According to the CAPS theory, personality itself is a complex organization of cognitive-affective units, including encodings, competencies, expectancies, values, and self-regulatory plans (Mischel \& Shoda, 1995). When a person is in a situation, the active psychological features of that situation activate a set of such internal cognitive-affective units. These cognitive-affective units in turn activate (or inhibit) other cognitive-affective units and, ultimately, certain behavioral manifestations. Individual differences may occur because persons have different thresholds for the activation of cognitions and affects and because persons have a different organization of cognitive-affective units. Different person types in the triple typology model may represent different CAPS, and the task of the personality psychologist is then to identify the relevant underlying cognitions and affects (and thresholds) that are common to the persons of the person type(s) under consideration and that are distinctive with respect to the persons of all other person types; Michel and Shoda called this finding the cognitive-affective domain map of the behavioral domain under consideration.

When one has identified the relevant features behind the classes of a triple typology model in terms of cognitive-affective units, situational features, and behavioral features, one may also try to interpret the hierarchical relations in terms of the same features. Hierarchical relations could, for instance, be interpreted in terms of different levels for one or several features. Also, the if-then rules of the model could be reformulated as if ( situation feature) then (behavior feature) rules. By relating the latter to the relevant CAPS variables, one may be able to discover the dynamics of the different person types and hence fashion theories of personality that relate the three typologies to one another (Bem, 1983).

These general principles are now illustrated for the triple typology model for self-reported hostility. In order to reveal the psychological mechanisms behind this model, we look for the active features of the situations, relevant cognitions and affects, and behavioral features. For the situational features, we start from the observation that frustration plays an important role in hostility (Feshbach \& Weiner, 1991; Mischel, 1993). Frustration is considered to be an interruption in goal-directed behavior of a person by which the attainment of a goal is delayed or blocked (Endler \& Hunt, 1968). Potentially relevant active situational features may be classified in terms of factors that refer to (a) the origin, (b) the nature, and (c) the consequences of the frustration. Cognitions about the origin or cause of the frustration may transform the meaning of the frustration (Mischel, 1993) and hence can influence the likelihood of hostile behavior (Feshbach \& Weiner, 1991). Internally caused frustration may affect a person's behavior in a different way than externally caused frustration, and the same holds for intentionally versus accidentally caused frustration (Feshbach \& Weiner, 1991). A primary factor relating to the nature of the frustration is the frustration amount (intensity, duration, or persistence). The amount of hostile behavior may be hypothesized to be directly related to the amount of frustration experienced by an organism in the situation (Feshbach \& Weiner, 1991). Besides the amount of frustration, the kind of frustration might also be relevant. For example, experiences that affect self-esteem or that are egothreatening can be hypothesized to be much more likely to elicit hostile behavior than frustration caused by physical threats (Feshbach \& Weiner, 1991). As to situational features referring to the consequences of the frustration, the severity of the expected consequences might be especially relevant, with more severe expected consequences more likely leading to hostile behavior.

For the cognitive-affective units, several person variables may be potentially relevant (Mischel, 1993; Mischel \& Shoda, 1995). Quantitative differences in hostility may be related to a hostile attribution bias, with a more hostile person tending to encode negative or aversive situations as purposefully aggressive, irrespective of the other's actual intent (Mischel, 1993). More hostile persons might also be less competent in constructing alternative solutions to problems (Mischel, 1993) and in inhibiting hostile behavior; stated otherwise, they might have less frustration tolerance. Differences in hostile behavior might also be related to differences in expectancies concerning hostile behaviors: Some persons may inhibit their hostility because they expect negative reactions or depreciation from others, whereas other persons may expect it to be better for their health to express their hostile feelings rather than bottling them up. With respect to values, some persons may believe that the expression of hostility is an indication of being assertive, which is highly valued in society. Finally, different persons may have different preferences about how to deal with their angry feelings: Some persons may prefer to suppress their angry feelings, whereas others may prefer to direct them toward persons or objects in the environment (Spielberger \& Sydeman, 1994).

For the behavioral features, a potentially relevant distinction is that between automatic, physiologically based behaviors and more "voluntary" controlled behaviors (Funder \& Colvin, 1991). Other potentially relevant behavioral features could be derived from Rosenzweig's (1944, 1976) distinction between the extrapunitive, intropunitive, and impunitive character of responses, based on whether the responses are directed, respectively, to the source of the frustration, to the subject himself or herself, or to neither of the two.

We now examine to what extent these person, situational, and behavioral features allow us to discriminate between the person, situation, and behavior classes of the triple typology model and to interpret the model's hierarchical relations and if-then rules.

\section{Method}

Situational and behavioral features. Ten judges, all staff members in the psychology department of the University of Leuven (6 men and 4 women), judged the 23 situations with respect to six situational features and the 15 behaviors with respect to six behavioral features. The 
situational features and their definitions as presented to the participants were the following:

Situational features related to the origin of the frustration:

1. Intentional-accidental cause of the frustration: The frustration in the situation can be intentionally or accidentally caused.

2. Internal-external locus of the cause of the frustration: The locus of the cause of the frustration in the situation can be situated inside or outside the person.

Situational features related to the nature of the frustration:

3. Persistence of frustration in the situation: The duration of the frustration in the situation can be long or rather short.

4. Ego-threatening character of the frustration: The frustration threatens the person's self and self-esteem.

5. Physically threatening character of the frustration: The frustration threatens the person's body or physical integrity.

Situational features related to the consequences of the frustration:

6. Consequences of frustration in the situation: The consequences of the frustration in the situation can be minimal or severe.

The behavioral features and their definitions as presented to the participants were the following:

1. Extrapunitive: The response to the frustration is directed to the source of the frustration.

2. Intropunitive: The response to the frustration is directed to the person himself or herself.

3. Impunitive: The response to the frustration is unrelated to the frustration.

4. Automatic reaction-intentional action: The response to the frustration is a purely automatic reaction versus a conscious intentional action undertaken by the person.

5. Physiologic: The response to the frustration is purely physiologic in nature.

6. Externally observable without tools: The response to the frustration can be observed by an external observer without tools.

The judgment task was computer administered. Each participant had to judge, first, the 23 situations with respect to the 6 situational features and, next, the 15 behaviors with respect to the 6 behavioral features. All situations (behaviors) first had to be judged with respect to the first feature, next with respect to the second feature, and so forth. The degree to which a situational (behavioral) feature was applicable to a situation (behavior) had to be marked on a 7-point scale that was labeled in terms of the feature involved. For the situations, 1 indicates that the frustration in the situation is intentionally caused, has an internal locus, is short, is not ego-threatening, is not physically threatening, and has minor consequences, and 7 indicates that the frustration is accidentally caused, has an external locus, is long, is ego-threatening, is physically threatening, and has major consequences. For the behaviors, 1 indicates that the response is not extrapunitive, not intropunitive, not impunitive, automatic, not physiologic, and not observable without tools, and 7 indicates that the response is to a large extent extrapunitive, intropunitive, impunitive, conscious-intentional, physiologic, and observable without tools. The two sets of features were presented in random order, and within each feature, the situations (behaviors) were presented in random order.
To check the interrater reliability of the feature judgments, Cronbach's coefficient alpha (for non-normalized data) was calculated per feature. For the situational features, all except one alpha value was above .90 . The alpha value for internal-external locus of the cause of the frustration was .83 , which is still acceptable. For the behavioral features, four features had alpha values above 90 . The alpha values for intropunitive (.50) and impunitive $(-.05)$, however, were considered too low and were eliminated from further analyses. The low reliabilities could be due to the fact that the exact meaning of the features in question was not clear for the judges or to restriction of range. Also, the $(3, k)$ intraclass correlations (Shrout \& Fleiss, 1979), with $k$ being the number of judges $(k=10)$, were calculated for the situations as well as for the behaviors and yielded similar results.

Person features. After the termination of the first study, the 54 participants from this study were recontacted by mail with the request to fill out two short questionnaires; 49 participants responded positively to this request. The first questionnaire was the Zelf-Analyse Vragenlijst (ZAV; Van Der Ploeg, Defares, \& Spielberger, 1982), the Dutch adaptation of the State-Trait Anger Scale (STAS; Spielberger, 1980), which is supposed to measure lack of frustration tolerance. The second questionnaire was a 21-item experimental questionnaire intended to measure seven cognitive-affective units concerning aggressive and hostile behavior, each of them being represented by three items. The seven cognitiveaffective units were:

1. Encodings: The degree to which aversive experiences are interpreted as purposefully aggressive, irrespective of the actual intent of the others with whom they interact (Mischel, 1993). Sample item: "When other people get me in trouble, I rapidly think they do it on purpose."

2. Competencies: The degree to which people are competent in regulating feelings and behaviors related to frustrating experiences. Sample item: "I am good in controlling myself when I experience frustration."

3. Expectancies about oneself: The degree to which not expressing angry feelings is expected to be unhealthy for oneself. Sample item: "Controlling yourself with respect to angry feelings is unhealthy, according to me."

4. Expectancies about others: The degree to which expressing angry feelings is expected to lead to negative reactions by others. Sample item: "I think that, in general, the expression of anger is not appreciated by others."

5. Values: The degree to which assertive behavior is considered to be important in frustrating situations. Sample item: "I find it important to stand up for your rights when you are in a situation in which you are frustrated."

6. Anger-in: The degree to which feelings of frustration are suppressed. Sample item: "I easily suppress feelings of frustration."

7. Anger-out: The degree to which feelings of frustration are expressed toward persons or objects in the environment. Sample item: "When I feel frustrated, I show it easily."

Persons had to indicate on a 7-point scale to what extent each statement applied to them $(1=$ not applicable at all, $7=$ applicable to a strong extent). A principal-components analysis was performed on the responses to the 21 items. The solution with three components was chosen as it explained $53.01 \%$ of the total variance. The selected solution was then subjected to a varimax rotation. The items with the highest positive (negative) loadings on this component were the three anger-out (anger-in) items; hence, this first component is labeled anger-out/anger- 
Table 2

Average Judgments of Situations With Respect to Six Situation Features

\begin{tabular}{|c|c|c|c|c|c|c|}
\hline \multirow[b]{2}{*}{ Situation class } & \multicolumn{6}{|c|}{ Situational feature } \\
\hline & SF1 & SF2 & SF3 & SF4 & SF5 & SF6 \\
\hline \multicolumn{7}{|l|}{ S3: High frustrating situations } \\
\hline $\begin{array}{l}\text { Your instructor unfairly accuses you of cheating } \\
\text { on an examination. }\end{array}$ & 4.00 & 6.20 & 6.10 & 6.30 & 1.10 & 6.40 \\
\hline \multicolumn{7}{|l|}{ S2: Moderately frustrating situations } \\
\hline \multicolumn{6}{|l|}{ You are waiting at the bus stop and the bus } & 3.30 \\
\hline $\begin{array}{l}\text { You miss your train because the clerk has given } \\
\text { you faulty information. }\end{array}$ & 3.20 & 6.60 & 4.40 & 1.60 & 1.50 & 4.10 \\
\hline $\begin{array}{l}\text { You are typing a term paper and your } \\
\text { typewriter breaks. }\end{array}$ & 1.60 & 6.40 & 3.70 & 1.50 & 1.10 & 4.80 \\
\hline \multicolumn{7}{|l|}{ You arrange to meet someone and he (she) } \\
\hline doesn't show up. & 4.30 & 6.30 & 4.20 & 4.80 & 1.10 & 3.40 \\
\hline \multicolumn{4}{|l|}{ You are trying to study and there is incessant } & 2.90 & 2.30 & 5.20 \\
\hline \multicolumn{7}{|l|}{ You are driving to a party and suddenly your } \\
\hline car has a flat tire. & 1.10 & 6.60 & 3.90 & 1.20 & 2.20 & 2.70 \\
\hline Someone has opened your personal mail. & 6.00 & 6.20 & 5.60 & 6.00 & 1.00 & 5.30 \\
\hline Someone makes an error and blames it on you. & 6.20 & 6.40 & 5.10 & 5.50 & 1.10 & 4.90 \\
\hline \multirow{2}{*}{\multicolumn{7}{|c|}{ You use your last 104 to call a friend and the }} \\
\hline $\begin{array}{l}\text { You use your last } 10 c \text { to call a friend and the } \\
\text { operator disconnects you. } \\
\text { Someone persistently contradicts you when you }\end{array}$ & & 5.20 & & 1.30 & 1.00 & 3.40 \\
\hline $\begin{array}{l}\text { Someone persistently contradicts you when you } \\
\text { know you are right. }\end{array}$ & 5.10 & 5.50 & 3.60 & 4.60 & 1.10 & 2.90 \\
\hline \multicolumn{7}{|l|}{ You have just found out that someone has told } \\
\hline lies about you. & 6.50 & 5.90 & 5.80 & 6.00 & 1.30 & 5.30 \\
\hline \multicolumn{7}{|l|}{ S1: Low frustrating situations } \\
\hline \multicolumn{7}{|l|}{ You are in a restaurant and have been waiting a } \\
\hline $\begin{array}{l}\text { You are reading a mystery and find that the last } \\
\text { page of the book is missing. }\end{array}$ & \multicolumn{5}{|c|}{ You are reading a mystery and find that the last } & 2.30 \\
\hline $\begin{array}{l}\text { You are talking to someone and he (she) does } \\
\text { not answer you. }\end{array}$ & 5.10 & 5.40 & 2.40 & 4.80 & 1.20 & 3.10 \\
\hline clothing. & 3.10 & 5.80 & 2.90 & 2.10 & 1.60 & 2.80 \\
\hline $\begin{array}{l}\text { Someone pushes ahead of you in a theater } \\
\text { ticket line. }\end{array}$ & 5.90 & 4.80 & 1.70 & 2.00 & 1.10 & 1.50 \\
\hline \multicolumn{6}{|l|}{ The grocery store closes just as you are about } & 2.70 \\
\hline $\begin{array}{l}\text { You are carrying a cup of coffee to the table } \\
\text { and someone bumps into you. }\end{array}$ & 2.20 & 5.40 & 2.50 & 1.40 & 3.20 & 2.40 \\
\hline $\begin{array}{l}\text { You accidently bang your shins against a park } \\
\text { bench. }\end{array}$ & 1.80 & 2.20 & 1.80 & 1.50 & 4.20 & 1.70 \\
\hline
\end{tabular}

Note. S1, S2, and S3 refer to Situation Classes 1, 2, and 3, respectively, and SF1 through SF6 refer to Situational Features 1 through 6 . SF1 $=$ intentional-accidental cause of the frustration; SF2 = internalexternal locus of the cause of frustration; SF3 = persistence of frustration; SF4 = ego-threatening character of the frustration; SF5 = physically threatening character of the situation; SF6 $=$ severity of the consequences of the frustration. A 7-point scale labeled in terms of the features was used; the number of judges was 10 . From "S-R Inventories of Hostility and Comparisons of the Proportions of Variance From Persons, Behaviors, and Situations for Hostility and Anxiousness," by N. S. Endler and J. M. Hunt, 1968, Journal of Personality and Social Psychology, 9, pp. 310-311. Copyright 1968 by the American Psychological Association. Adapted by permission of the author.

in. The second component is labeled hostile encoding as the items with the highest positive loading on this component were the three encoding items. Finally, the items with the highest positive (negative) loadings on the third component were the expectancies about others (self) items; this component is labeled as expected negative effects of expressingsuppressing hostility.

\section{Results and Discussion}

Table 2 presents for all situations, grouped by situation class, the values for the six situational features, averaged over the 10 judges. Visual inspection indicates that two situational features are prominent in discriminating between the three classes: per- 
Table 3

Average Judgments of Behaviors With Respect to Four Behavioral Features

\begin{tabular}{|c|c|c|c|c|}
\hline \multirow[b]{2}{*}{ Behavior class } & \multicolumn{4}{|c|}{ Behavioral feature } \\
\hline & $\mathrm{BF} 1$ & BF2 & BF3 & $\mathrm{BF} 4$ \\
\hline \multicolumn{5}{|l|}{ B1: Facial hostile reactions } \\
\hline Turn away & 5.10 & 5.50 & 2.10 & 5.50 \\
\hline Grimace & 3.80 & 4.80 & 3.70 & 6.50 \\
\hline \multicolumn{5}{|l|}{ B2: Attack reactions } \\
\hline Want to strike something or someone & 5.10 & 4.30 & 3.00 & 2.80 \\
\hline Grind teeth & 3.00 & 2.60 & 4.20 & 4.40 \\
\hline \multicolumn{5}{|l|}{ B4: Cursing } \\
\hline Curse & 4.70 & 4.00 & 2.40 & 6.90 \\
\hline \multicolumn{5}{|l|}{ B3: Blocking reactions } \\
\hline Hands tremble & 2.10 & 1.20 & 6.10 & 5.00 \\
\hline Perspire & 1.90 & 1.00 & 6.90 & 4.10 \\
\hline Emotions disrupt actions & 2.40 & 1.00 & 5.00 & 2.30 \\
\hline Splutter & 2.30 & 1.60 & 4.20 & 6.20 \\
\hline \multicolumn{5}{|l|}{ B5: Augmented arousal } \\
\hline Heart beats faster & 2.10 & 1.00 & 6.90 & 1.70 \\
\hline Want to shout & 3.10 & 3.20 & 3.00 & 2.40 \\
\hline \multicolumn{5}{|l|}{ B6: General hostile reactions } \\
\hline Become tense & 2.50 & 1.40 & 5.80 & 3.40 \\
\hline Become enraged & 4.90 & 3.00 & 3.90 & 5.10 \\
\hline Lose patience & 4.20 & 2.50 & 2.10 & 3.80 \\
\hline Feel irritated & 3.40 & 1.70 & 4.10 & 2.50 \\
\hline
\end{tabular}

Note. B1 through B6 refer to Behavior Classes 1 through 6, and BFI through BF4 refer to Behavioral Features 1 through $4 . \mathrm{BF1}=$ extrapunitive; $\mathrm{BF} 2$ = automatic reaction-intentional action; $\mathrm{BF} 3=$ physiologic; BF4 = externally observable without tools. A 7-point scale labeled in terms of the features was used; the number of judges was 10 . From "S-R Inventories of Hostility and Comparisons of the Proportions of Variance From Persons, Behaviors, and Situations for Hostility and Anxiousness," by N. S. Endler and J. M. Hunt, 1968, Journal of Personality and Social Psychology, 9, p. 311. Copyright 1968 by the American Psychological Association. Adapted by permission of the author.

sistence and severity of consequences; on both features the rating of the single situation of Situation Class S3 exceeds all other situations, whereas, with a very small number of exceptions, all situations of Situation Class S2 exceed all situations of Situation Class S1. The scores of the S2 and S1 situations were further compared with two-tailed $t$ tests. Significant differences were found for persistence, $t(18)=-4.78, p=.0001$, and severity of consequences, $t(18)=-4.85, p=.0001$. A two-group canonical discriminant analysis with the situational features as predictors and membership to Situation Class 1 or Situation Class 2 as the criterion was performed and yielded correlations of .92 and .93 , respectively, between persistence and severity of consequences and the first canonical variable. In a two-group stepwise discriminant analysis, severity of the consequences appeared to be the only situational feature that was retained to discriminate between the situation classes, $F(1,18)=23.49$, $p=.0001$. These results indicate that there are only quantitative differences between the situation classes, which are related to the consequences of the frustration. The situation hierarchy can therefore be interpreted as a quantitative severity of consequences dimension on which the three classes S1, S2, and S3 take a low, moderate, and high position, respectively.

Table 3 presents for all behaviors, grouped by behavior class, the values for the four behavioral features, averaged over the 10 judges. In view of the low numbers of behaviors per class, statistical tests of differences between individual classes were not called for. Visual inspection of Table 3 indicates, however, that Behavior Classes B1, B2, and B4 contain more extrapunitive, conscious, intentional responses, whereas Behavior Classes B3, B5, and B6 contain more automatic, physiological responses. Two-tailed $t$ tests of the difference between these two clusters of behavior classes confirmed this hypothesis: For automatic reaction versus intentional action, $t(13)=-4.92, p=$ .0003 ; for extrapunitive, $t(13)=-2.71, p=.018$; and for physiological, $t(13)=2.19, p=.048$. A two-group canonical discriminant analysis with the four behavioral fealures as predictors and membership in the two above-mentioned clusters as the criterion yielded correlations of $.97, .72$, and -.62 , respectively, between the above-mentioned behavioral features and the first canonical variable. In addition, a two-group stepwise discriminant analysis was performed; in this analysis, automatic reactions versus intentional actions was the only behavioral feature that was retained to discriminate between the two behavior clusters, $F(1,14)=24.19, p=.0003$.

On the basis of the results on situational and behavioral features, the if ( situation class) then (behavior class) rules of the triple typology model can be reformulated in feature terms. For example ( see Table 1), it holds that if a person of Person Type 3 faces a situation that involves frustration with minor consequences ( $\mathrm{S} 1$ ), then this person, unlike a person of Person Type 7, will not display hostile behavior. However, when a person of Person Type 3 faces a situation that involves frustration with severe consequences (S3), then this person will display automatic hostile reactions ( $\mathrm{B} 3, \mathrm{~B} 5$, and $\mathrm{B} 6$ ). In the same situation, a person of Person Type 7 will display both conscious, intentional actions and automatic responses.

As regards the person features, we first examine the aggregated behavior level (see Table 1, last column) at which the seven person types collapse into three general person categories (I, II, and III, comprising Person Types 3, 2-6, and 1-4-5-7, respectively), which differ in the severity of the consequences needed in order to become hostile. Persons of Person Category I only display hostile behavior in severely frustrating situations (S3), persons of Person Category II in moderately and severely frustrating situations ( $\mathrm{S} 2$ and $\mathrm{S} 3$ ), and persons of Person Category III in all frustrating situations ( $\mathrm{S} 1, \mathrm{~S} 2$, and $\mathrm{S} 3$ ); hence, Person Categories I, II, and III are labeled as low, moderately, and severely hostile person categories, respectively. Table 4 presents, for all individual and aggregated person types, the average scores on frustration tolerance ( $\mathrm{ZAV}$ ) and on the three cognitive-affective components, anger-out/anger-in, hostile encoding, and expected negative effects of expressing-suppressing hostility. Visual inspection of this table indicates that, on the aggregated behavior level, persons of Person Category I have a lower score on hostile encoding $(-.64)$ and frustration tolerance (ZAV; 17.43) than persons of Person Category II ( -.11 and 18.64, respectively), who in turn have lower scores than the persons of Person Category III (.24 and 18.83), the difference on hostile encoding between I and III being significant, $t$ (35) $=-2.15, p=.038$. A three-group canonical discriminant analysis with frustration tolerance and the three cognitive-affective 
Table 4

Average Scores of the Persons of the Different Person Types With Respect to Four Cognitive-Affective Units

\begin{tabular}{|c|c|c|c|c|c|}
\hline Person type & $n$ & $\begin{array}{l}\text { Frustration } \\
\text { tolerance } \\
\text { (ZAV) }\end{array}$ & $\begin{array}{l}\text { Component 1: } \\
\text { Anger-out/in }\end{array}$ & $\begin{array}{c}\text { Component } 2: \\
\text { Hostile } \\
\text { encoding }\end{array}$ & $\begin{array}{c}\text { Component 3: } \\
\text { Expected negative } \\
\text { effects of expressing- } \\
\text { suppressing hostility }\end{array}$ \\
\hline $\begin{array}{c}\text { Person Category I: } \\
\text { Low hostile }\end{array}$ & & & & & \\
\hline Person Type 3 & 7 & 17.43 & -.12 & -.64 & -.01 \\
\hline $\begin{array}{l}\text { Person Category II: } \\
\text { Moderately hostile } \\
\text { Person Type } 2 \\
\text { Person Type } 6\end{array}$ & $\begin{array}{r}11 \\
3 \\
8\end{array}$ & $\begin{array}{l}18.64 \\
18.67 \\
18.63\end{array}$ & $\begin{array}{l}-.33 \\
-.52 \\
-.25\end{array}$ & $\begin{array}{l}-.11 \\
-.47 \\
-.03\end{array}$ & $\begin{array}{l}.32 \\
.08 \\
.41\end{array}$ \\
\hline $\begin{array}{c}\text { Person Category III: } \\
\text { Severely hostile } \\
\text { Person Type } 1 \\
\text { Person Type } 4 \\
\text { Person Type } 5 \\
\text { Person Type } 7\end{array}$ & $\begin{array}{r}30 \\
5 \\
3 \\
12 \\
10\end{array}$ & $\begin{array}{l}18.83 \\
21.00 \\
15.00 \\
18.33 \\
19.50\end{array}$ & $\begin{array}{r}-.18 \\
.07 \\
.16 \\
-.15 \\
.62\end{array}$ & $\begin{array}{r}.24 \\
1.07 \\
.09 \\
.10 \\
.04\end{array}$ & $\begin{array}{r}-.07 \\
.23 \\
-.34 \\
-.19 \\
.00\end{array}$ \\
\hline
\end{tabular}

Note. $\quad$ ZAV = Zelf-Analyse Vragenlijst (Van Der Ploeg, Defares, \& Spielberger, 1982; State-Trait Anger Scale [STAS]).

component scores as predictors and membership to Person Category I, II, or III as a criterion was performed. Hostile encoding had the highest correlation (.70) with the first canonical variable, the mean scores on this variable for Person Categories I, II, and III being $-.66,-.51$, and .34 , respectively. In a threegroup stepwise discriminant analysis, hostile encoding was the only person variable that entered the analysis, $F(2,45)=2.60$, $p=.086$. This means that persons of Person Category III are more inclined to encode frustrating situations as purposefully caused aggressive (and hence display more hostile behavior in such situations) than are the persons of the other person categories.

Beyond the aggregated level, a seven-group canonical discriminant analysis was performed with frustration tolerance and the three cognitive-affective component scores as predictors and the seven person types as a criterion. The first canonical variable was interpreted as hostile encoding because the hostile encoding component had the highest correlation (.78) with that variable; the second canonical variable was interpreted as suppressed anger as it had moderate to high correlations with frustration tolerance ( $\mathrm{ZAV} ; .63$ ), hostile encoding (.56), and expected negative effects of expressing-suppressing hostility (.41). Considering the person types with the most extreme scores on these canonical variables yields a meaningful interpretation of (at least a part of) the person typology. On the first canonical variable, persons of Person Types 1,3 , and 4 have mean scores of $.88,-.72$, and .75 , respectively, meaning that persons of Person Type 3 are less inclined to encode frustrating situations in a hostile way than are persons of Person Types 1 and 4. This accounts for the fact that persons of Person Type 3 only display hostile behaviors in situations with severe consequences (S3) whereas persons of Person Types 1 and 4 display hostile behavior in all situations (S.1, S2, and S3; see Table 1). Person Types 1 and 4, however, markedly differ in terms of expectancies in that persons of Person Type 1, unlike persons of Person Type 4, expect negative effects of expressing their anger, the two person types having mean scores of .72 and -1.00 , respectively, on the second canonical variable. This may account for the fact that persons of Person Type 4 display attack reactions (B2) in situations with moderate or severe consequences whereas this is not the case for persons of Person Type 1 (see Table 1).

\section{General Discussion}

From a theoretical viewpoint, the model presented in this article is a response to Bem's (1983) challenge to construct theories of the triple typology. Persons, situations, and behaviors are organized in three hierarchical typologies of persons, situations, and behaviors, which are related to one another by different sets of if-then rules (Wright \& Mischel, 1987). The model results in a parsimonious representation that allows one to grasp the complex interplay between persons, situations, and behaviors. As such, it may be a useful tool to describe individual differences in situation-behavior profiles as advocated by authors such as Golding (1975), Olweus (1976), Shoda et al. (1993, 1994), and Wright and Mischel (1987).

A second important theoretical aspect is to reveal, beyond a formal and parsimonious representation, the psychological mechanisms at the basis of the three typologies and their interrelations (e.g., Golding, 1975; Mischel \& Peake, 1982; Mischel \& Shoda, 1995; Olweus, 1976; Shoda et al., 1994). We have shown how this can be done by relating the triple typology model to active psychological features of situations, behaviors, and persons. A particularly interesting type of person feature appears to be features, such as hostile encoding, that may be considered to refer to dispositional, conditional, process-related constructs. Dispositional relates to the fact that the constructs concern sta- 
ble personality characteristics; those entail the advantage of being parsimoniously summarizable in a single position on an underlying dimension. Conditional refers to the fact that the constructs in question entail an implicit or explicit if -then relation (Wright \& Mischel, 1987), such as, in the case of hostile encoding, "If the person faces a frustrating situation, then that frustration is easily perceived as intentionally caused'; such conditional constructs are particularly relevant for contextualized approaches to the study of individual differences. Processrelated indicates the fact that the constructs in question directly refer to psychological (e.g., cognitive or affective) processes, such as, in the case of hostile encoding, a perception-interpretation process. It may be particularly useful to relate similar process-related features to a triple typology model, because the latter, in itself, is a purely structural model dealing with mechanistic rather than dynamic interactions (Endler, 1982). As is shown in this article, relating process-related features to a triple typology model makes it possible to interpret the person types of the model as systems of cognitive-affective units (with distinct activation thresholds) that mediate between active situation features and behavioral manifestations (Mischel \& Shoda, 1995). For example, in the hostility study, for a certain person type, unlike for other person types, a frustrating situation with moderate consequences may activate the hostile encoding unit beyond the threshold of that unit for that person type, resulting in turn in various conscious or automatic hostile behavioral manifestations.

From a practical viewpoint, it is important to emphasize that when the triple typology model is applied to real Person $x$ Situation $\times$ Behavior data, the resulting model strongly depends on the samples of situations and behaviors chosen. The situation is similar to what Block (1995), within the context of factor analytic research, has called the problem of prestructuring. In this respect, it may be noted that the application included in the present article was an exploratory study with self-report data from an existing, unstructured questionnaire. The triple typology methodology, however, can also be used with questionnaire or behavioral data collected with a set of situations or behaviors with an a priori conceptual design. Within this context, it may be noted that a confirmatory version of the triple typology algorithm is available (Leenen et al., in press); for data with an a priori conceptual structure this may be particularly useful.

A second practical aspect refers to the fact that a triple typology data analysis involves a number of somewhat arbitrary choices, including the choice of the complexity (or rank) of the final model (for an overview of relevant guiding rules in this respect, see Van Mechelen, De Boeck, \& Rosenberg, 1995). Again, the situation is similar to that of factor analysis (and in particular the choice of the number of factors there; Block, 1995). As to a comparison with factor analysis, however, it may be noted that the triple typology approach meets a number of criticisms raised with respect to that technique (Block, 1995), including the fact that the triple typology approach operates on raw data rather than on derived correlation coefficients (and hence avoids the psychometric problems associated with the latter); the fact that the approach, unlike factor analysis, accounts for asymmetrical, conditional relations; and the fact that it represents inter- as well as intraindividual behavioral differences.

Summarizing, the triple typology framework may be a useful aid in describing and analyzing the structure and dynamics of Person $\times$ Situation $\times$ Behavior data. Beyond the analysis of real data, however, it may offer a formal tool to sharpen thinking on the complex interplay of persons, situations, and behaviors in many behavioral domains. As such, it may contribute to the construction and refinement of contextualized theories of personality.

\section{References}

Allport, G. W. (1937). Personality: A psychological interpretation. New York: Holt.

Alston, W. P. (1975). Traits, consistency, and conceptual alternatives for personality theory. Journal for the Theory of Social Behavior, 5, 1748.

Asendorpf, J. B. (1988). Individual response profiles in the behavioral assessment of personality. European Journal of Personality, 2, 155167.

Bem, D. J. (1983). Constructing a theory of the triple typology: Some (second) thoughts on nomothetic and idiographic approaches to personality. Journal of Personality, 53, 566-577.

Block, J. (1995). A contrarian view of the five-factor approach to personality description. Psychological Bulletin, 117, 187-215.

Cantor, N., \& Mischel, W. (1979). Prototypicality and personality: Effects on free recall and personality impressions. Journal of Research in Personality, 13, 187-205.

Cantor, N., Mischel, W., \& Schwartz, J. C. (1982). A prototype analysis of psychological situations. Cognitive Psychology, 14, 45-77.

Carroll, J. D., \& Arabie, P. (1983). Indclus: An individual differences generalization of the Adclus model and Mapclus algorithm. Psychometrika, 48, 157-169.

Claeys, W., Timmers, L., \& Phalet, K. (1993). Stable individual differences in situation-behavior, construct-behavior, and goal-behavior relations. European Journal of Personality, 7, 139-158.

De Boeck, P., \& Rosenberg, S. (1988). Hierarchical classes: Model and data-analysis. Psychometrika, 53, 361-381.

De Boeck, P., Rosenberg, S., \& Van Mechelen, I. (1993). The hierarchical classes approach: A review. In I. Van Mechelen, J. Hampton, R. S. Michalski, \& P. Theuns (Eds.), Categories and concepts: Theoretical views and inductive data analysis (pp. 265-286). London: Academic Press.

De Boeck, P., \& Van Mechelen, I. (1990). Traits and taxonomies: A hierarchical classes approach. European Journal of Personality, 4, $147-156$.

Endler, N. S. (1982). Interactionism: A personality model, but not yet a theory. In M. M. Page (Ed.), Nebraska Symposium on Motivation: Vol. 30. Personality-Current theory and research (pp. 155-200). Lincoln: University of Nebraska Press.

Endler, N. S., \& Hunt, J. M. (1968). S-R inventories of hostility and comparisons of the proportions of variance from persons, behaviors, and situations for hostility and anxiousness. Journal of Personality and Social Psychology, 9, 309-315.

Feshbach, S., \& Weiner, B. (1991). Personality (3rd ed.). Lexington, MA: Heath.

Funder, D. C., \& Colvin, C. R. (1991). Explorations in behavioral consistency: Properties of persons, situations, and behaviors. Journal of Personality and Social Psychology, 60, 773-794.

Gati, I., \& Tversky, A. (1982). Representations of qualitative and quantitative dimensions. Journal of Experimental Psychology: Human Perception and Performance, 8, 325-340. 
Golding, S. L. (1975). Flies in the ointment: Methodological problems in the analysis of the percentage of variance due to persons and situations. Psychological Bulletin, 82, 278-288.

Hampson, S. E., John, O. P., \& Goldberg, L. R. (1986). Category breadth and hierarchical structure in personality: Studies of asymmetries in judgments of trait implications. Journal of Personality and Social Psychology, 51, 37-54.

Hunt, J. M., Cole, M.-L. W., \& Reis, E. E. S. (1958). Situational cues distinguishing anger, fear, and sorrow. American Journal of Psychology, $71,138-151$.

John, O. P., Hampson, S. E., \& Goldberg, L. R. (1991). The basic level in personality-trait hierarchies: Studies of trait use and accessibility in different contexts. Journal of Personality and Social Psychology, $60,348-361$.

Leenen, I., Van Mechelen, I., De Boeck, P., \& Rosenberg, S. (in press). INDCLAS: A three-way hierarchical classes model. Psychometrika.

Levin, J. (1965). Three-mode factor analysis. Psychological Bulletin, $64,442-452$

Mischel, W. (1993). Introduction to personality (5th ed.). Orlando, FL: Harcourt Brace.

Mischel, W., \& Peake, P. (1982). Beyond déjà vu in the search for cross-situational consistency. Psychological Review, 89, 730-755.

Mischel, W., \& Shoda, Y. (1995). A cognitive-affective system theory of personality: Reconceptualizing situations, dispositions, dynamics, and invariance in personality structure. Psychological Review, 102, 246-268.

Murtha, T. C., Kanfer, R., \& Ackerman, P. L. (1996), Toward an interactionist taxonomy of personality and situations: An integrative situational-dispositional representation of personality traits. Journal of Personality and Social Psychology, 71, 193-207.

Ogilvie, D. M., \& Ashmore, R. D. (1991). Self with other representations as unit of analysis in self-concept research. In R. Curtis (Ed.), The relational self (pp. 282-314). New York: Guilford Press.

Olweus, D. (1976). A critical analysis of the "modern" interactionist position. In D. Magnusson \& N. S. Endler (Eds.), Personality at the crossroads. Current issues in interactional psychology (pp. 221233). Hillsdale, NJ: Erlbaum.

Pervin, L. A. (1976) . A free-response description approach to the analysis of person-situation interaction. Journal of Personality and Social Psychology, 34, 465-474.

Price, R. H., \& Bouffard, D. L. (1974). Behavioral appropriateness and situational constraint as dimensions of social behavior. Journal of Personality and Social Psychology, 30, 579-586.

Reid, A., \& Deaux, K. (1996). Relationship between social and personal identities: Segregation or integration? Journal of Personality and Social Psychology, 71, 1084-1091.

Rosch, E., Mervis, C. B., Gray, W. D., Johnson, D. M., \& Boyes-Braem, P. (1976). Basic objects in natural categories. Cognitive Psychology; $8,382-439$.
Rosenberg, S. (1989). A study of personality in literary autobiography: An analysis of Thomas Wolfe's Look Homeward, Angel. Journal of Personality and Social Psychology, 56, 416-430.

Rosenberg, S., Van Mechelen, I., \& De Boeck, P. (1996). A hierarchical classes model: Theory and method with application in psychology and psychopathology. In P. Arabie, L. J. Hubert, \& G. De Soete (Eds.), Clustering and classification (pp. 123-155). Singapore: World Scientific.

Rosenzweig, S. (1944). An outline of frustration theory, In J. M. Hunt (Ed.), Personality and the behavior disorders. (Vol. 1, pp. 379-388). New York: Ronald Press.

Rosenzweig, S. (1976). Aggressive behavior and the Rosenzweig picture-frustration (P-F) study. Journal of Clinical Psychology, 32, 885891.

Schutte, N. S., Kenrick, D. T., \& Sadalla, E. K. (1985). The search for predictable settings: Situational prototypes, constraint, and behavioral variation. Journal of Personality and Social Psychology, 49, $121-$ 128.

Shoda, Y., Mischel, W., \& Wright, J. C. (1993). The role of situational demands and cognitive competencies in behavior organization and personality coherence. Journal of Personality and Social Psychology, 65, 1023-1035.

Shoda, Y., Mischel, W., \& Wright, J. C. (1994). Intraindividual stability in the organization and patterning of behavior: Incorporating psychological situations into the ideographic analysis of personality. Journal of Personality and Social Psychology, 67, 674-687.

Shrout, P. E., \& Fleiss, J. L. (1979). Intraclass correlations: Uses in assessing rater reliability. Psychological Bulletin, 86, 420-438.

Spielberger, C. D. (1980). Preliminary manual for the State-Trait Anger Scale (STAS). Tampa: University of South Florida, Human Resources Institute.

Spielberger, C. D., \& Sydeman, S. J. (1994). State-Trait Anxiety Inventory and State-Trait Anger Expression Inventory. In M. E. Maruisch (Ed.), The use of psychological tests for treatment planning and outcome assessment (pp. 292-321). Hillsdale, NJ: Erlbaum.

Van Der Ploeg, H. M., Defares, P. B., \& Spielberger, C. D. (1982). ZelfAnalyse Vragenlijst (ZAV) [State-trait anger scale (STAS)]. Lisse, the Netherlands: Swets \& Zeitlinger.

Van Mechelen, I., De Boeck, P., \& Rosenberg, S. (1995). The conjunctive model of hierarchical classes. Psychometrika. 60, 505-521.

Wright, J. C., \& Mischel, W. (1987). A conditional approach to dispositional constructs: The local predictability of social behavior. Journal of Personality and Social Psychology, 55, 454-469.

Zuroff, D. C. (1982). Person, situation, and person-by-situation interaction components in person perception. Journal of Personality, 50, 1 14.

Received May 7, 1997

Revision received March 24, 1998

Accepted April 9, 1998 